\title{
Knock-down of calcitonin receptor expression induces apoptosis and growth arrest of prostate cancer cells
}

\author{
SHIBU THOMAS, A. MURALIDHARAN and GIRISH V.SHAH \\ Pharmacology, University of Louisiana School of Pharmacy, College of Health Sciences, Monroe, LA 71209, USA
}

Received April 16, 2007; Accepted June 4, 2007

\begin{abstract}
Calcitonin (CT) and its receptor (CTR) are expressed only in basal epithelium of benign prostate and in whole epithelium of malignant prostates. Also, CT and CTR mRNA levels in prostate cancers increase with an increase in tumor grade. We tested the role of the CT/CTR autocrine axis on the tumorigenicity of prostate cancer cells. We enforced the expression of CTR in CT-positive/CTR-deficient PC-3 cells. In contrast, we knocked down CTR expression in CT/CTRpositive PC-3M cells. The effect of CTR modulation on the oncogenicity was evaluated by the rate of cell proliferation, invasion, colony formation and in vivo growth in nude mice. Up-regulation of CTR in PC-3 cells and its down-regulation in PC-3M cells significantly altered their tumorigenicity. Intratumorally administered CTR RNAi in preexisting PC-3M xenografts markedly attenuated their further growth. This treatment also led to a remarkable decrease in endothelial cell populations in the tumors and increase in apoptotic, PCNAnegative cell populations. Tumors receiving CTR RNAi treatment displayed markedly lower levels of urokinase-type plasminogen activator, phospho-Akt and survivin, suggesting CTR activates uPA-uPAR axis and PI-3-kinase-Akt-survivin pathway. These results suggest an important role for CT-CTR autocrine axis in the progression of localized prostate tumor to a metastatic phenotype, and offer a potential therapeutic option for invasive cancers.
\end{abstract}

\section{Introduction}

Prostate cancer is the most commonly diagnosed cancer and the second leading cause of cancer deaths in men in America $(1,2)$. Although androgen ablation therapy is effective in men with advanced disease for some time, the disease subsequently progresses to lethal, untreatable androgen-independent, metastatic and chemoresistant form (3-5). This tumor progression

Correspondence to: Dr Girish V. Shah, Department of Pharmaceutical Sciences, School of Pharmacy, University of Louisiana, 700 University Avenue, Monroe, LA 71209, USA

E-mail:shah@ulm.edu

Key words: calcitonin, receptor, knock-down, tumor growth is usually associated with several genetic, morphological and phenotypical changes in tumor cells such as hormone resistance and increased expression of neuroendocrine peptides (4,6-9).

The transcripts of neuropeptide calcitonin (CT) and its receptor (CTR) have been detected exclusively in basal epithelium of human prostate, but are completely absent in the luminal compartment. However, these transcripts become detectable in secretory epithelium of malignant prostates as early as high-grade premalignant intraepithelial neoplasia (PIN), and progressively increase with increase in tumor grade (10). These results suggest that the aberrant expression of CT/CTR expression in malignant epithelial cells may be associated with their neoplastic transformation. In a recent study, we have shown that CT-deficient but CTR-positive and non-tumorigenic LnCaP cells become tumorigenic with enforced CT expression (11). To investigate the importance of CTR and identify CTR-mediated signaling in CT-stimulated tumorigenicity of $\mathrm{PC}$ cell lines, we enforced the expression of CTR in CTR-deficient PC-3 cells, and knocked it down in CTR-positive PC-3M cells under in vitro as well as in vivo conditions. Our results suggest that the enforced CTR expression in PC-3 cells dramatically enhanced their oncogenicity. In contrast, the knock-down of CTR expression in PC-3M cells markedly reduced it. The present results that the activation of CT-CTR autocrine axis raises the tumorigenicity of PC cell lines are consistent with our earlier results (11), but also provide new and significant information that in vivo knockdown of CTR in preexisting PC-3M xenografts led to growth arrest of tumors, and this may have resulted from the transition of actively proliferating cell populations to growth arrest and apoptosis. Loss of functional CTR in these xenografts also led to a marked decline in endothelial cell populations of the tumors, decrease in the levels of phosphorylated Akt, survivin and urokinase-type plasminogen activator (uPA), suggesting CTR-mediated oncogenesis may involve PI-3-kinase (PI3K)Akt signaling, activation of uPA-uPA receptor axis and angiogenesis.

\section{Materials and methods}

\section{Reagents and antibodies}

Animals. Male balb/c nu/nu mice (6-8 weeks old; Harlan, Madison, WI) were maintained two per cage in microisolator units on a standard sterilizable laboratory diet (Teklad Labchow, Harlan Teklad, Madison, WI). Animals were housed 
under humidity- and temperature-controlled conditions, and the light-dark cycle was set at 12-h intervals. Mice (22-24 g) were quarantined 1 week before the experimental manipulations. All protocols for in vivo studies were reviewed and approved by the Institutional Animal Care and Use Committee of the University of Louisiana.

Cell culture. The PC-3M prostate cancer cell line was kindly provided by Dr Isiah Fidler (Anderson Cancer Center, Houston, TX). The cells were maintained in the complete medium (RPMI-1640 medium supplemented with 5\% fetal calf serum and $15 \%$ horse serum, $100 \mathrm{IU} / \mathrm{ml}$ penicillin $\mathrm{G}$ and $100 \mu \mathrm{g} / \mathrm{ml}$ streptomycin) under standard culture conditions. PC-3 cells were obtained from ATCC (Manassas, VA) and cultured as recommended by the ATCC.

\section{Plasmids}

Constitutively active pcDNA-CTR vector. PC-3 cells express CT mRNA and secrete CT, but do not endogenously express CTR (10). We enforced CTR expression by stable transfection of a constitutively active vector expressing CTR. A fulllength human CTR cDNA was cloned from oligo-dT-purified mRNA extracts of LNCaP cells by reverse transcriptionPCR as previously described (10). The cloned cDNA was inserted into mammalian expression vector pcDNA3.1-TOPO (Invitrogen) in a sense direction. The sense orientation of the insert in the cloned plasmid was confirmed by sequencing at the institutional DNA sequencing facility. CTR cDNApcDNA3.1 construct was transfected into PC-3 cell lines using FuGene 6 transfection reagent (Roche, Indianapolis, IN). The vehicle control cells (PC-3EV) received the empty vector $(\mathrm{EV})$. G418-resistant colonies were isolated after culture in the selection media for 3 weeks, and were further expanded.

Construction of small hairpin RNAi-expressing plasmid to silence CTR expression. Previous studies from this laboratory tested four different siRNA duplexes against CTR mRNA for CTR knock-down in PC-3M cells. Among these, the following siRNA duplexes of sense and antisense sequences were found to be either scrambled (no knock-down) or most potent (>90\% decline in CTR mRNA): scrambled siRNA sequence, 5'-gcac ugcccugacuacuucuu-3' and 5'-P-gaaguagucagggcagugcuu-3'; most potent siRNA sequence, $5^{\prime}$-caaaugcuaugaccggauuuu-3' and 5'-P-aauccggucauagcauuuguu-3'.

Small interfering oligonucleotides of these sequences were synthesized, annealed, and inserted between $\mathrm{H} 1$ promoter (on 5 -end of the siRNA insert) and green fluorescence protein (GFP) and hygromycin resistance genes (at the 3'-end, Genescript, Piscataway, NJ). The empty vector (EV) and scrambled vector (SV) controls have been tested in multiple cell lines and do not demonstrate any toxicity to cells as demonstrated by MTT assay after transfection and have no effect on the expression of housekeeping genes, GAPDH and B-actin.

Knock-down of CTR expression in PC-3M cells. Exponentially growing PC-3M cells were plated at a density of $2 \times 10^{5}$ cells per well in a six-well plate and cultured for $24 \mathrm{~h}$. The transfection with the empty vector (PC3M-EV), vector carrying scrambled siRNA insert (PC-3M-SV) or that carrying the most potent siRNA insert (PC-3M-CTR-) was carried out by lipofection using FuGene reagent (Roche, Indianapolis, IN). Stable transfectants were selected using Hygromycin ${ }^{\text {TM }}$ selection over a period of five weeks as described previously (11). The selected clones were visualized by GFP expression, and further characterized by the quantitation of CTR mRNA abundance using real-time PCR and membrane CT receptors with ${ }^{125} \mathrm{I}-\mathrm{CT}$ radioligand receptor binding assays.

Monitoring of CTR expression: real time polymerase chain reaction ( $R T-P C R)$. Total RNA ( $1 \mu \mathrm{g}$ per sample) from the cell lines was reverse transcribed in $20 \mu \mathrm{l}$ using $150 \mathrm{ng}$ oligo (dT) 15 primers, $1 \mathrm{mM}$ deoxynucleotide triphosphates and $15 \mathrm{U}$ of AMV reverse transcriptase as recommended by the manufacturer (Promega). The RT reaction products were then diluted (50-5,000 times) and subjected to real-time PCR. The PCR was performed in a $50-\mu 1$ reaction using $5 \mu 1$ of the diluted first-strand cDNA template, optimized amounts of primers, water, and $25 \mu 1$ of the $2 \mathrm{X} \mathrm{IQ}^{\mathrm{TM}} \mathrm{SYBR}-$ Green supermix (Bio-Rad). All PCR reactions were cycled at $50^{\circ} \mathrm{C}$ for $2 \mathrm{~min}$, $94^{\circ} \mathrm{C}$ for $5 \mathrm{~min}$, and 40 cycles of $94^{\circ} \mathrm{C}$ for $30 \mathrm{sec}, 57^{\circ} \mathrm{C}$ for $1 \mathrm{~min}$ and $68^{\circ} \mathrm{C}$ for $2 \mathrm{~min}$. All PCR products were in the linear range of the exponential phase of PCR amplification. The quantity of CTR transcripts obtained from standard curve was normalized to that of the GAPDH in the same sample. All PCR reactions were performed in duplicates and at three doses of cDNA template. Ct values were determined, and the -fold change in mRNA abundance was calculated as described previously (12).

The sequences of primer pairs were as follows: CTR, 5'-at cgaggtccaaaccaccgtgaagc-3' and 5'-cagtattgacaaggagcaccetg-3'; GAPDH, 5'-acgccgcatcttcttgtgc-3' and 5'-acagccgcatcttcttgt gc-3'.

\section{Radioligand assay for membrane CTR}

Membrane preparation. Cultured PC-3-EV, PC-3-CTR, PC3M-EV, PC-3M-SV or PC-3M-CTR- cells in 100-mm dishes were detached with $0.05 \%$ EDTA in PBS, harvested, and suspended in cytoplasmic lysis buffer (10 mM HEPES, $10 \mathrm{mM}$

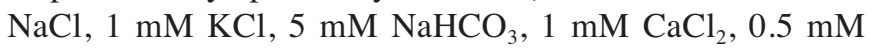
$\mathrm{MgCl}_{2}, 1 \mathrm{mM}$ PMSF, $100 \mathrm{U} / \mathrm{ml}$ aprotinin, $5 \mathrm{mM}$ EDTA), and homogenized by 50 strokes in a dounce homogenizer. The homogenate was centrifuged at $1000 \mathrm{x} \mathrm{g}$ for $5 \mathrm{~min}$, and the supernatant was recentrifuged at $15,000 \mathrm{x}$ g for $7 \mathrm{~min}$ to obtain membrane fraction. Protein concentration was determined by Bio-Rad assay, and the membranes were aliquoted and stored frozen at $-70^{\circ} \mathrm{C}$.

Radioligand binding assay. The ${ }^{125} \mathrm{I}$-mono-iodinated sCT of high specific activity was prepared as previously described (13). Membranes ( $1 \mu \mathrm{g} /$ protein/tube) were incubated with increasing concentrations of ${ }^{125} \mathrm{I}-\mathrm{sCT}$ in the assay buffer (25 mM Tris, $10 \mathrm{mM} \mathrm{MgCl}_{2}, 1 \mathrm{mM}$ EGTA, $0.25 \mathrm{mM}$ PMSF, $0.85 \mathrm{mg} / 100 \mathrm{ml}$ aprotinin, $0.85 \mathrm{mg} / 100 \mathrm{ml}$ leupeptin) for $1 \mathrm{~h}$ at $4^{\circ} \mathrm{C}$. The total assay volume was kept at $50 \mu \mathrm{l}$. The membrane fraction was collected after extensive washings and the radioactivity of the bound hormone was determined. The binding data was further analyzed by non-linear regression and scatchard analysis using the computer program Prism ${ }^{\mathrm{TM}}$ (Graphpad $^{\mathrm{TM}}$, San Diego, CA). 
Effect of CTR expression modulation on oncogenicity of PC cell lines

Proliferation of PC-3 and PC-3M sublines: 3-(4,5-dimethylthiazol-2-yl)-2,5-diphenyltetrazolium bromide (MTT) assay. The growth of PC-3-EV, PC-3-CTR, PC-3M-EV and PC-3MCTR- sublines was measured by an MTT assay kit (ATCC). Exponentially growing cells were plated in a 96-well plate at a density of $8 \times 10^{3}$ cells per well, and allowed to attach for $24 \mathrm{~h}$. Complete growth medium was then replaced with $100 \mu 1$ of RPMI serum-free medium (Gibco-Invitrogen, NY) and culture was continued at $37^{\circ} \mathrm{C}$ under $5 \% \mathrm{CO}_{2}$. After 24 or $48 \mathrm{~h}$ of culture, the cells were treated with MTT solution at $37^{\circ} \mathrm{C}$ for $4 \mathrm{~h}$. The color reaction was stopped by the addition of solubilization/stop solution (100 $\mu \mathrm{l} /$ well) and incubation at $37^{\circ} \mathrm{C}$ was continued to completely dissolve the formazan product. Absorbance of the samples was determined at $595 \mathrm{~nm}$ with an ELISA plate reader (Bio-Rad, Hercules, CA).

In vitro invasion assay. These experiments were conducted in 24-well, two compartmented, Matrigel ${ }^{\mathrm{TM}}$ invasion chambers (Becton Dickinson, Bedford, MA). Exponentially growing PC-3M cells (or transfectants) were serum-starved for $24 \mathrm{~h}$ with basal RPMI medium containing no serum or growth factors (but containing 0.1\% BSA, $10 \mathrm{mM}$ HEPES, $4 \mathrm{mM}$ L-glutamine, $100 \mathrm{IU} / \mathrm{ml}$ penicillin $\mathrm{G}$ and $100 \mu \mathrm{g} / \mathrm{ml}$ streptomycin). The cells were then harvested, and seeded at a density of $25 \times 10^{3}$ cells/well in the upper insert of the Matrige ${ }^{\mathrm{TM}}$ invasion chamber. The lower chamber received the chemoattractant medium, which consisted of $90 \%$ basal RPMI medium and $10 \%$ conditioned medium from the cultures of PC-3 M cells expressing constitutively active Gs $\alpha$ protein (14). The incubations were carried out for $24 \mathrm{~h}$, after which the Matrigel ${ }^{\mathrm{TM}}$ (along with non-invading cells) was scraped off with cotton swabs, and the outer side of the insert was fixed and stained using Diff Quik staining (Dade Behring Diagnostics, Aguada, PR). The number of migrated cells on the outer bottom side of the insert were counted under the microscope in six or more randomly selected fields (magnification, $\mathrm{x} 100)$. The final results were expressed as mean \pm SEM per $\mathrm{x} 100$ field. Each experiment was performed in triplicates, and the experiment was repeated twice.

Growth correction. Since some PC-3M cell variants exhibit a high proliferation rate, it is likely that the cells that migrated early during the 24-h incubation period could proliferate during the remaining period of incubation, leading to a slight overestimation of the final results. To correct this probability, we determined the growth rate of PC-3M cells under identical culture conditions. Cells $\left(25 \times 10^{3}\right)$ were plated at hourly intervals in six-well dishes and cultured with/without CT $(50 \mathrm{nM})$ for $1-24 \mathrm{~h}$. The mean percent increase in the cell number was determined at the end of the incubation period by counting the net increase in the number of cells. The relative CT-induced increase of the pooled results of all time points was found to be 1.19 (vehicle control =1). This correction was applied to the results of invasion assays.

Soft agar colony formation assays. Soft agar assays were performed as described previously (14). An underlay of $0.5 \%$ agar in RPMI-1640 medium containing 5\% FCS was prepared by mixing equal volumes of $1 \%$ agarose and 2X RPMI-1640 plus $10 \%$ FCS. Two $\mathrm{ml}$ of this mixture was pipetted into the wells of six-well plates and allowed to set. Cells $\left(5 \times 10^{3}\right)$ were seeded in each well of a 6-well culture dish containing $0.3 \%$ top low-melt agarose. The agarose was allowed to set, and the plates were incubated in a humidified chamber at $37^{\circ} \mathrm{C}$ for 14 days. Colonies were counted in a blinded manner using a $\mathrm{x} 4$ objective on a Zeiss inverted microscope. Data are expressed as average number of colonies formed as well as average diameter of colonies.

Tumor xenografts in nu/nu mice. Nude athymic male mice were injected subcutaneously (sc) with cell lines $\left(1 \times 10^{6}\right.$ cells/ mouse) as described in the Results section and maintained on a laboratory diet ad libitum for 5 weeks. Tumor size was measured every 3-4 days by a caliper. The tumor volumes were determined by using the formula: $\mathrm{V}=(\mathrm{L} * \mathrm{~W} * \mathrm{H})$. After 5 weeks, tumors were removed, weighed, fixed in neutral buffered formalin and embedded in paraffin. The 5- $\mu \mathrm{m}$ thick sections of the tumors were analyzed by the presence of GFP immunofluorescence, H\&E staining or immunohistochemistry as described in the Results section. Six to eight mice were used for each cell line.

Intratumoral administration of CTR RNAi. PC-3M cells were inoculated subcutaneously in a group of nude mice. Day 9 post-implantation, the mice were randomly divided into two treatment groups of four animals each: one group received the intratumoral injections of the SV vector; the other group received the vector expressing CTR RNAi on days 9, 17 and 23 post-implantation.

For intratumoral injections of plasmids expressing CTR RNAi or scrambled RNAi, $20 \mu \mathrm{g}$ of plasmid DNA $(1 \mathrm{mg} / \mathrm{ml})$ was diluted in $30 \mu 1$ of sterile HBSS. Lipofectamine 2000 (20 $\mu 1$ ) was added to $30 \mu 1$ of sterile HBSS in another tube. The DNA/lipid complex was prepared by mixing diluted DNA and lipid followed by a gentle vortexing to yield a DNA:lipid ratio of $1: 1$. The mixture was left at room temperature for $15 \mathrm{~min}$. This $100 \mu \mathrm{l}$ DNA-lipid mixture was then injected into the center of pre-established tumor via insulin syringe (28 gauge, 0.5-inch needles; Becton Dickinson, Franklin Lake, NJ). These conditions were determined after initial tries with multiple variations in DNA:lipid ratio. Efficiency of transfection was determined by the expression of reporter protein (green fluorescence protein). The optimized protocol used in the study led to GFP expression in approximately $65-70 \%$ of the tumor cells.

The mice were sacrificed 10 days after the last dose of RNAi treatment, as was necessitated by the morbidity resulting from the tumors that had formed in control groups. The size of the tumors was measured by calipers every 3 days. Tumors were dissected and weighed, and their gross morphology was examined. A 100\% incidence of tumors was observed in mockand SV-treated groups. Although CTR RNAi treatments did not inhibit tumor growth completely, the weights of the tumor masses were significantly smaller than those receiving SV vector. The effectiveness of CTR knock-down treatment was evaluated by CTR immunofluorescence of tumor sections as well as real-time PCR analysis for CTR transcripts in reversetranscribed RNA of tumor samples. 


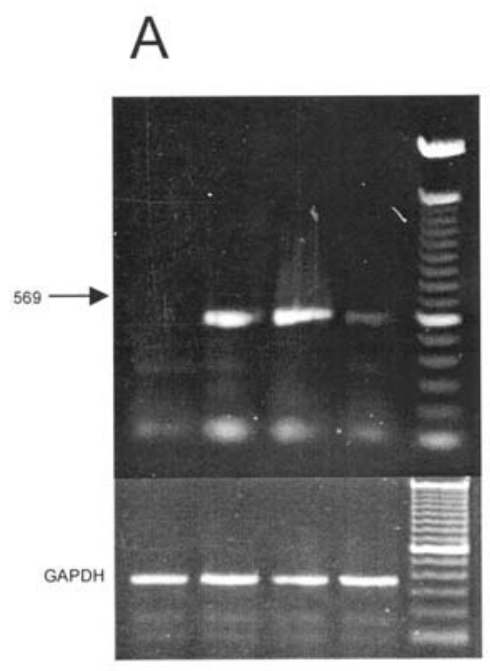

PC-3-EV PC-3-CTR PC-3M-EV PC-3M-CTR-
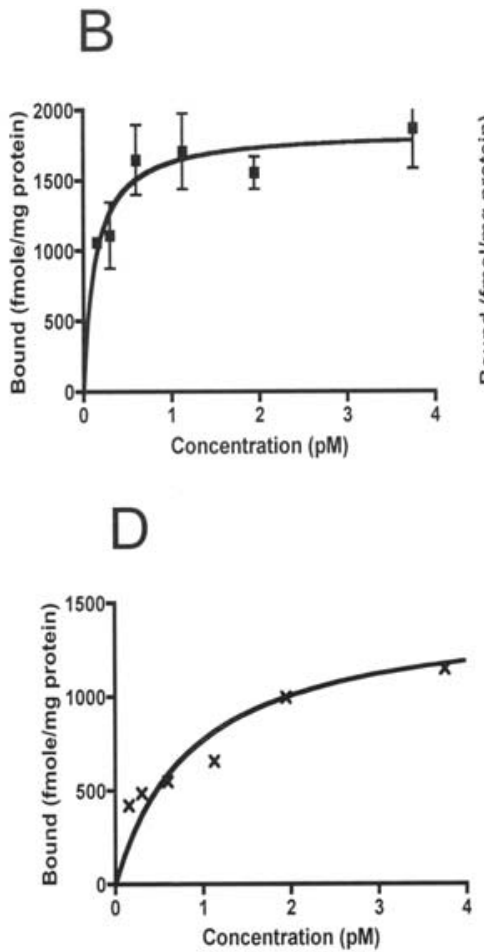

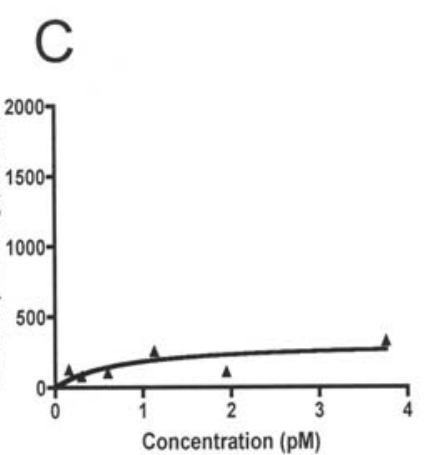

E

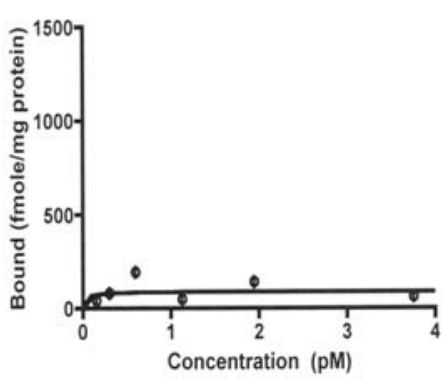

Figure 1. CTR mRNA abundance in PC-3M and PC-3 sublines and saturation analysis of ${ }^{125}$ I-sCT binding to PC-3 and PC-3M subline membranes. (A) Typical ethidium bromide-stained gel depicting the abundance of CTR and GAPDH mRNAs in various PC-3 and PC-3M sublines as described in the Results section. The mRNA levels for CTR and GAPDH were amplified by RT-PCR using specific amplimers as described in the Materials and methods section. The experiment was repeated three separate times and similar results were obtained. (B-E) Membranes of PC-3 and PC-3M sublines ( $1 \mu \mathrm{g}$ protein/tube) were incubated with increasing concentrations of ${ }^{125} \mathrm{I}-\mathrm{sCT}$ in the absence/presence of unlabeled sCT $(1 \mu \mathrm{M})$ as described in the Materials and methods section. Data points in B and C represent specific bound radioactivity in membranes of PC-3M-SV and PC-3M-CTR-cells respectively, whereas the data for PC-3-CTR and $\mathrm{PC}-3-\mathrm{EV}$ sublines are presented in D and $\mathrm{E}$ respectively.

Immunofluorescence studies with tumor xenografts. Tumor xenografts collected at the time of necropsy were fixed in neutral buffered formalin and embedded in paraffin as previously described (15). Approximately $5-\mu \mathrm{m}$ thick sections were cut, and the sections were first evaluated for GFP by immunofluorescence because the injected plasmid ( $\mathrm{SV}$ as well as CTR RNAi) expresses GFP. Next, the sections were evaluated for CTR immunofluorescence. The sections were deparaffinized, hydrated, and treated with blocking solution for $30 \mathrm{~min}$ at room temperature. The sections were then incubated with the anti-CTR rabbit serum for the first incubation at $4^{\circ} \mathrm{C}$ for $24 \mathrm{~h}$. The negative controls received an equivalent amount of normal rabbit serum. After removal of primary antisera, the sections were treated with TRITC-conjugated anti-rabbit secondary antibodies (1:500) for $1 \mathrm{~h}$ at room temperature in a light-sealed moist chamber. After several washes, the sections were subjected to a final incubation with DAPI (1:45000, Molecular Probes) for $10 \mathrm{~min}$ at room temperature.

To investigate whether decreases in the masses of CTR RNAi-treated tumors were due to growth arrest or apoptosis, we examined tumor sections for PCNA immunohistochemistry (IHC) and TUNEL analysis using an Apoptag immunofluorescence kit. The manufacturer's instructions were followed.

To examine whether CTR knock-down arrested tumor growth by attenuating angiogenesis, we performed von Willebrand Factor immunohistochemistry.

Digital images of high power field (x400) taken by a Nikon Optiphot-2 microscope were captured on a G4 Power PC computer by a Retiga $2300^{\mathrm{TM}}$ monochrome digital camera using an IPLab ${ }^{\mathrm{TM}}$ image analysis program (Scanalytics Inc.). The images for each field were captured in two colors (red and blue) separately. At least ten random images per section were obtained. When the images of a same field in the same section were taken in different colors, they were merged using colocalization module of the IPLAb ${ }^{\mathrm{TM}}$ software package. The percentage of specific antigen-positive cells in each specimen was also determined by counting immunopositive and total cells in at least ten $\mathrm{x} 400$ fields per specimen.

Statistical analysis. The results were statistically evaluated by one-way ANOVA analysis, and the levels of significance were derived from Newman-Keuls test. The difference was considered statistically significant when $\mathrm{p}<0.05$.

\section{Results}

Characterization of CTR expression in PC cell lines. As reported earlier, PC-3-EV cells (empty vector) lacked CTR transcripts (10), but stable expression of pcDNA3.1-CTR plasmid in PC-3-CTR cells led to high abundance of CTR mRNA levels (Fig. 1A, lanes 1 and 2). On the other hand, PC-3-MEV cells (transfected with vector expressing scrambled RNAi) expressed high levels of CTR transcripts, which declined to undetectable levels in PC-3M-CTR-cells (Fig. 1A, lanes 3 and 4). All cell lines expressed similar levels of GAPDH mRNA, suggesting that the changes in the transcript 
Table I. Quantitative RT-PCR for CTR transcripts in PC-3 and PC-3M sublines (Fig. 1A).

\begin{tabular}{lcccl}
\hline Sample & $\begin{array}{c}\text { Threshold } \\
\text { position }\end{array}$ & Ct value & $\Delta \Delta$ Ct value & $\begin{array}{l}\text { Relative } \\
\text { value }\end{array}$ \\
\hline PC-3M-SV & 15 & 25.43 & 0 & 1.0 \\
& 15 & 25.82 & 0 & 1.0 \\
PC-3M-CTR- & 15 & 28.53 & -0.9331 & 0.11629 \\
& 15 & 28.64 & -0.848 & 0.141 \\
PC-3-EV & 15 & 32.51 & 0 & 1.0 \\
& 15 & 31.80 & 0 & 1.0 \\
PC-3 CTR & 15 & 26.58 & 3.59 & 60.54 \\
& 15 & 26.26 & 3.16 & 46.52 \\
\hline
\end{tabular}

levels were CTR gene-specific. Quantitative estimation of CTR transcripts by real-time PCR revealed that the knockdown of CTR gene expression in PC-3M cells led to $88 \%$ decline in CTR mRNA in relative abundance; conversely, enforced expression of the CTR gene in PC-3 cells led to an approximately 50-fold increase in relative abundance of CTR mRNA (Table I).

Binding characteristics of CTR in $P C-3$ and $P C-3 M$ variants. Large changes in CTR mRNA abundance should result in similar changes in the concentrations of CTR in these sublines. However, only CTR molecules on the plasma membrane can bind to their ligands to activate oncogenic signaling. Therefore, we examined the binding characteristics of the CTR in plasma membrane fractions of these sublines by radioligand saturation assays using monoiodinated ${ }^{125} \mathrm{I}-\mathrm{sCT}$. Plasma membranes of PC-3-EV, PC-3-CTR, PC-3M-SV and PC-3M-CTR- cells were incubated with ${ }^{125} \mathrm{I}-\mathrm{sCT}$ under saturation conditions (Fig. 2). The knock-down of CTR expression in PC-3M cells caused a decrease in the Bmax from $3.12 \mathrm{fmol} / \mathrm{mg}$ protein (for PC-3M-SV) to $0.155 \mathrm{fmol} / \mathrm{mg}$ protein (for PC-3M-CTR-), a decline of 20-fold (Fig. 1B-C). In contrast, the enforced CTR expression in PC-3 cells increased Bmax from 0.09 $\mathrm{fmol} / \mathrm{mg}$ protein (for PC-3-EV) to $3.48 \mathrm{fmol} / \mathrm{mg}$ protein (for PC-3-CTR) (Fig. 1E and D respectively).

Effects of CTR modulation on the oncogenicity of PC cell lines. We examined the impact of enforced CTR expression or its knock-down on the oncogenicity of PC-3 and PC-3M sublines by assessing their rate of cell proliferation, invasion
A.

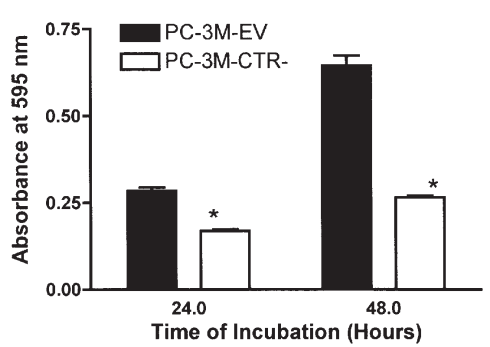

C.

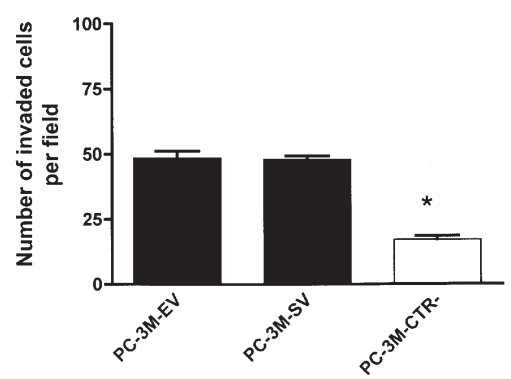

B.

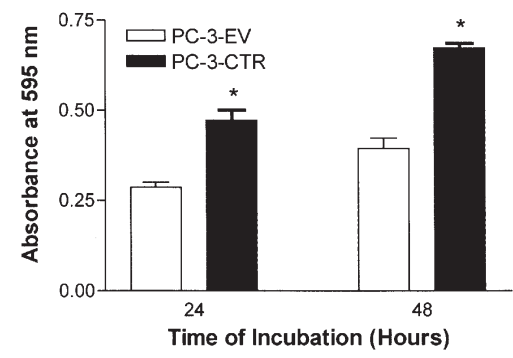

D.

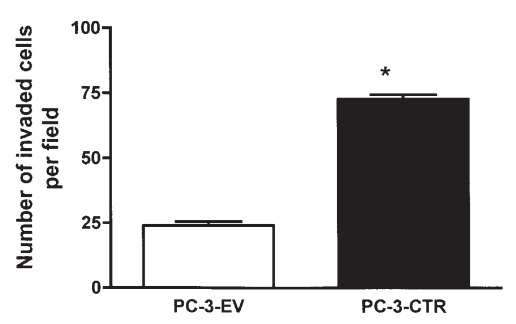

Figure 2. CTR expression and proliferation and invasion of prostate cancer cells. (A) PC-3M-EV and PC-3M-CTR- cells were cultured, and serum-starved for $24 \mathrm{~h}$. Then, their cell proliferation was assessed by the 3-(4,5-dimethylthiazol-2-yl)-2,5-diphenyltetrazolium bromide assay. Absorbance at 595 nm was measured, and error bars signify the mean \pm SEM of four independent experiments $(n=8)$. *Significantly decreased over the PC-3M-EV values; $\mathrm{p}<0.05$ (oneway ANOVA and Newman-Keuls test). (B) PC-3-EV and PC-3-CTR cells were cultured as described in A and their cell proliferation was determined. Absorbance at $595 \mathrm{~nm}$ was measured, and error bars signify the mean \pm SEM of four independent experiments (n=8). *Significantly increased over the PC-3EV values; p<0.001 (one-way ANOVA and Newman-Keuls test). (C) Invasion of PC-3M-EV, PC-3M-SV, and PC-3M-CTR- was examined as described in the Materials and methods section. Triplicate experiments were performed, and six x100 fields were counted for each data point. Results are expressed as mean \pm SEM for cells per $x 100$ field ( $n=3$ independent experiments $x 6$ fields). ${ }^{*}$ Significantly different from the controls (PC-3M-EV and PC-3M-SV) $\mathrm{p}<0.01$ (one-way ANOVA and Newman-Keuls test). (D) Invasion of PC-3-EV and PC-3-CTR was examined as described in the Materials and methods section. Triplicate experiments were performed, and six x100 fields were counted for each data point. Results are expressed as mean \pm SEM for cells per x100 field ( $\mathrm{n}=3$ independent experiments x 6 fields). *Significantly increased over the respective controls (PC-3-EV vs. PC-3-CTR); p<0.05 (one-way ANOVA and Newman-Keuls test). 
A.

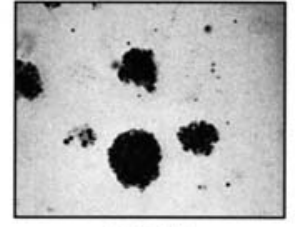

PC-3M

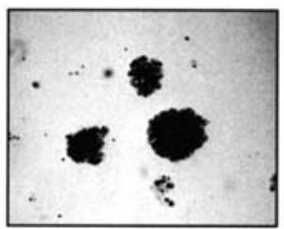

PC-3M-EV

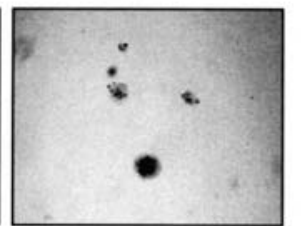

PC-3M-CTR-
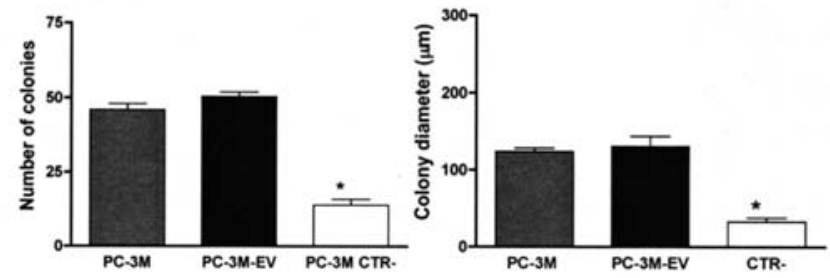

B.

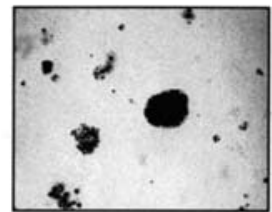

PC-3

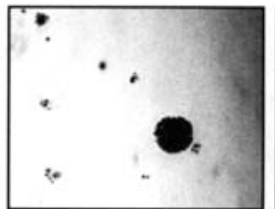

PC-3-EV

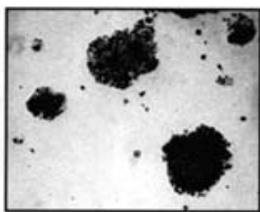

PC-3-CTR
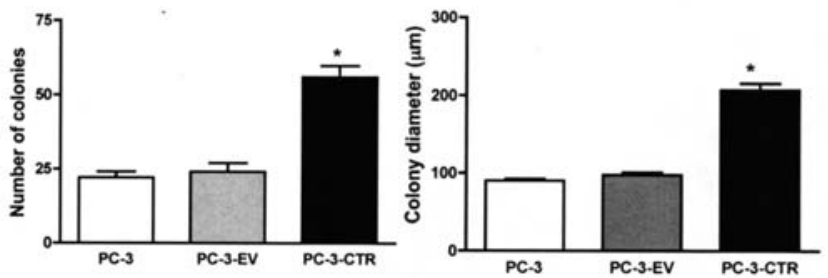

Figure 3. CTR expression and colony-forming ability of PC-3 and PC-3M variants. Modulation of CTR expression in PC-3 and PC-3M cells resulted in large changes in their anchorage-independent growth. Approximately $5000 \mathrm{PC}-3 \mathrm{M}$ cell variants were plated on soft agar as described in the Materials and methods section. (A) Typical photomicrographs (x100) show the colonies formed by PC-3M, PC-3M-EVand PC-3M-CTR-cells respectively. Pooled data of the mean number of colonies \pm SEM $(n=4)$ and mean diameter of these colonies \pm SEM $(n=4)$ is provided in the accompanying graphs. ${ }^{*}$ Significantly decreased over the control (PC-3M and PC-3M-EV) p<0.001 (one-way ANOVA and Newman-Keuls test). (B) Effect of CTR expression on colony-forming ability of PC-3EV variants. Typical photomicrographs (x100) show the colonies formed by PC-3, PC-3-EV and PC-3-CTR cells respectively. Pooled data of the mean number of colonies \pm SEM $(n=4)$ and mean diameter of these colonies \pm SEM $(n=4)$ is provided in the accompanying graphs. ${ }^{*}$ Significantly increased over the control (PC-3 and PC-3-EV) p $<0.001$ (one-way ANOVA and Newman-Keuls test).

through Matrigel ${ }^{\mathrm{TM}}$, and ability to form colonies on soft agar and xenografts in nude mice.

Effect on cell proliferation. The effects of these modifications were first examined in cell growth by the 3-(4,5-dimethylthiazol-2-yl)-2,5-diphenyltetrazolium bromide assays. The results of Fig. 2A reveal that the knock-down of CTR expression in PC-3M cells led to a moderate but significant decline in proliferation of $\mathrm{PC}-3 \mathrm{M}$ cells. In contrast, the enforced expression of CTR in PC-3 cells resulted in a significantly higher proliferation rate (Fig. 2B).

Effects on invasion through Matrigel. The results of Fig. 2C demonstrate that vector controls (PC-3MEV and PC-3MSV) displayed similar invasion through Matrigel invasion chambers. Knock-down of CTR expression reduced their invasiveness by $>2$-fold (Fig. 2C). Invasive activity of PC-3EV cells was comparable to PC-3M-CTR- cells, but increased by almost three-fold with enforced CTR expression (Fig. 2D).

Effect on colony formation in soft agar. We next evaluated the contribution of CTR on colony formation in soft agar as an in vitro measure of tumorigenicity (Fig. 3). High tumorigenicity of PC-3M cells was suggested by the formation of a large number of colonies, and the expression of empty vector (PC3M-EV) did not alter this ability when assessed by the average number of colonies and their diameter. However, the knockdown of CTR expression led to a 3-fold decline in the ability of PC-3M cells to form colonies (Fig. 3A). In contrast, the enforced CTR expression in PC-3 cells increased their colonyforming ability by 4 -fold. (Fig. 3B).
Effect on in vivo tumor growth. To demonstrate the importance of CTR in tumorigenicity of prostate cancer cells in vivo, we conducted xenograft studies in nude mice using PC-3M, PC3M-EV, PC-3M-CTR-, PC-3-EV and PC-3-CTR cells. The results presented in Fig. 4A show that parental $\mathrm{PC}-3 \mathrm{M}$ and PC-3M-EV cells showed similar in vivo growth profile, but PC-3M-CTR- cells displayed minimal growth. In contrast, enforced CTR expression significantly increased in vivo tumor growth of PC-3 cells (Fig. 4B). At the end of five weeks, the mice were sacrificed, and the tumors were dissected and weighed. The results show that PC-3M cells and PC-3M cells expressing carrier plasmid formed similar tumor masses at the necropsy but tumors formed by PC-3M-CTR- cells displayed a 99\% decline (Fig. 4C). PC-3-EV cells formed tumor xenografts, but enforced CTR expression increased in vivo tumor growth (Fig. 6B). At the necropsy, tumor masses of PC-3CTR cells were 2.5-fold greater than those of PC-3EV cells (Fig. 4D).

Intratumoral administration of CTR RNAi attenuates in vivo tumor growth of pre-existing tumors. Next, we tested the possibility that the knock-down of CTR expression in preexisting PC-3M xenografts will inhibit their growth. For this experiment, we first implanted PC-3M cells in nude mice and allowed them to form xenografts for 9 days. At this time, the tumors were small but visible, and could be palpated. We then began the administration of lipofected plasmids expressing either scrambled or CTR RNAi by intratumoral injections (as depicted by arrows in Fig. 5A). The plasmid also expressed green fluorescence protein (GFP) as a reporter protein. The results presented in Fig. 7A demonstrate that the weekly injections of CTR RNAi consistently suppressed tumor growth 
A.

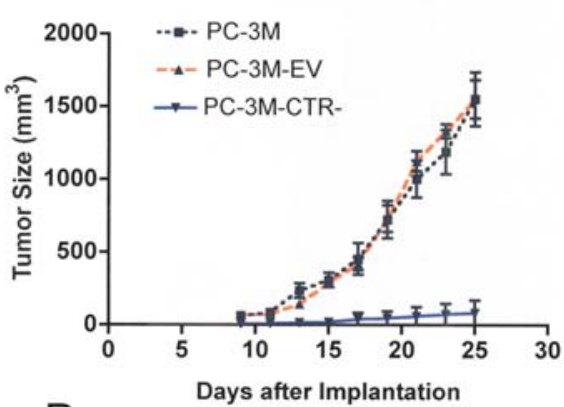

B.

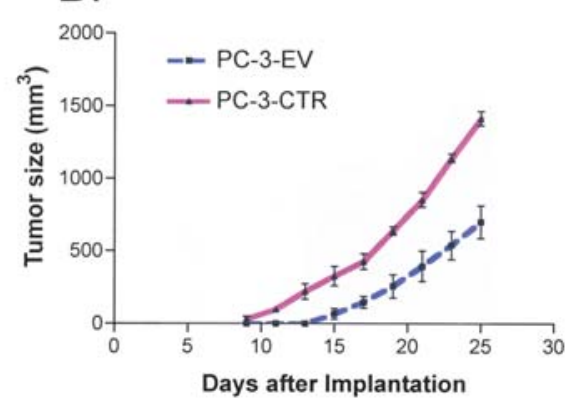

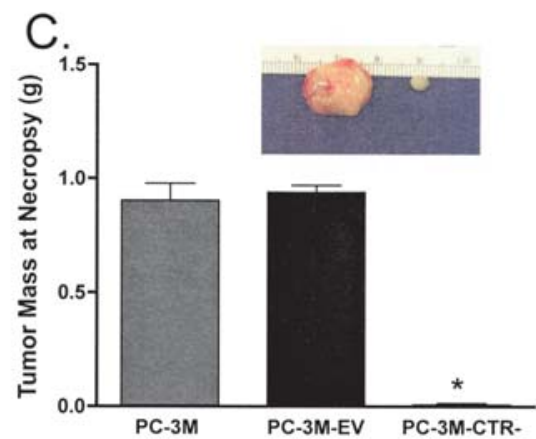

D.

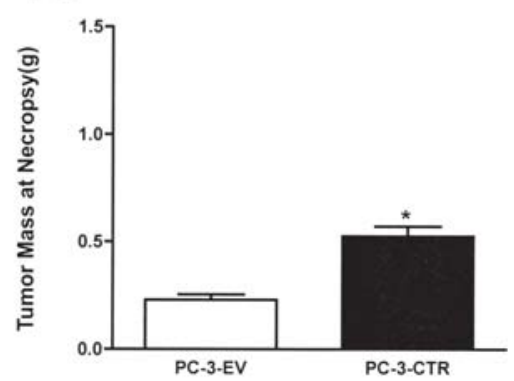

Figure 4. CTR expression and in vivo growth by PC sublines. (A and B) PC-3M and PC-3-derived sublines were injected subcutaneously into nude mice as described in the Materials and methods section. The tumor size was measured every alternate day by vernier calipers from day 9 to day 25 after the transplantation. The line graphs provide the growth profile of tumors as tumor size vs. the number of days after the implantation. (C and D) The mice were sacrificed five weeks after tumor cell implantation, tumor masses were removed and weighed after the removal of blood and connective tissues. The bar graphs present the mass of these tumors at necropsy (mean g tumor mass \pm SEM for $n=6$ ). Representative photograph of a set of PC-3M-EV and PC-3MCTR- tumors after necropsy shown in the inset. *Significant change from the respective controls, p<0.05 (one-way ANOVA and Newman-Keuls test).

A.

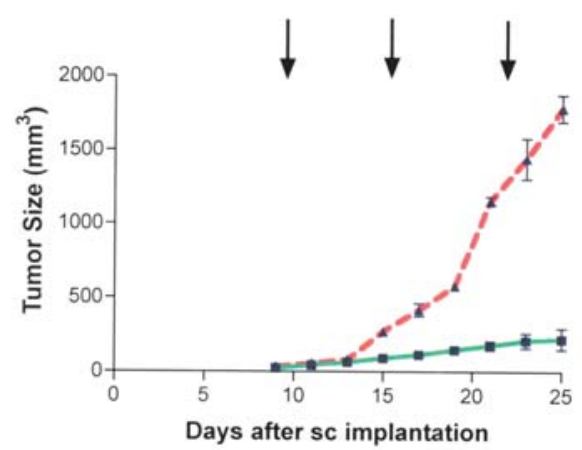

C. sv

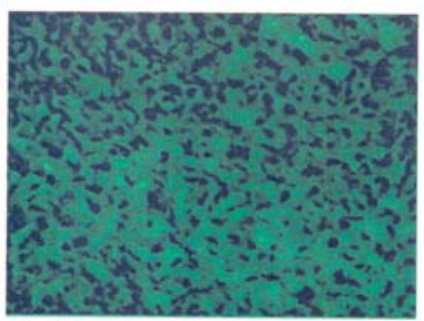

B.

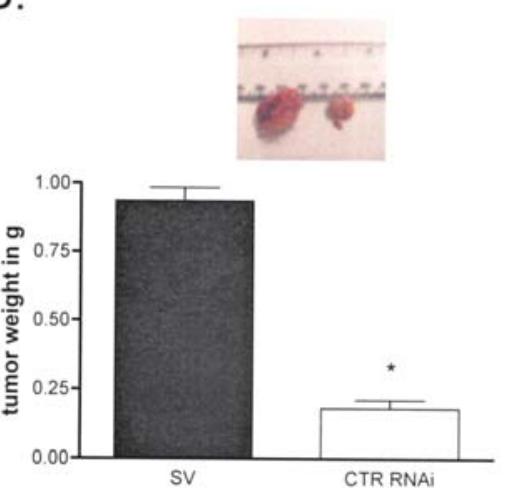

D.

CTR RNAi

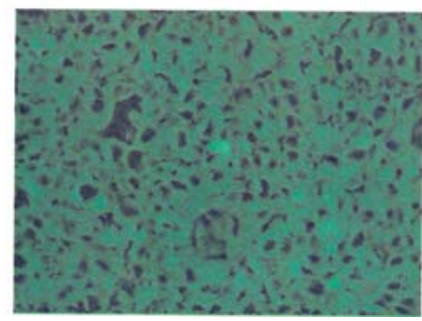

Figure 5. Intratumoral administration of CTR RNAi to nude mice transplanted with PC-3M cells. (A) PC-3M cells were subcutaneously implanted in nude mice as described in the Materials and methods section and were allowed to grow. The plasmids were mixed with lipofectamine and injected intratumorally on days 9,16 and 23 post-implantation (indicated by arrows). The tumor growth was measured until day 35 . Controls received the plasmid containing inactive CTR siRNA sequence (SV). Six mice were included in each treatment group. (B) Tumor masses at the necropsy. Each bar represents triplicate analyses of mean $\pm \mathrm{SD}$, where the significant difference from controls is represented by an asterisk $(\mathrm{p}<0.05)$. Representative photograph of a set of SV and CTR-RNAi treated PC-3M tumors after necropsy shown in the inset (C and D). It is apparent that a significant number of cells in the tumors injected with SV (C) or CTR RNAi plasmid (D) displayed abundant green fluorescence. 


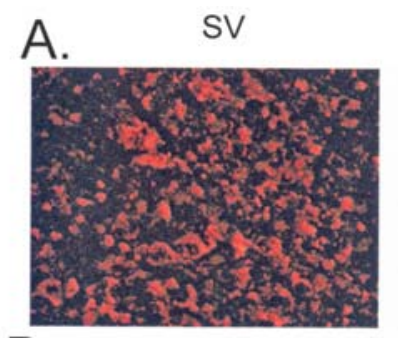

B.

SV

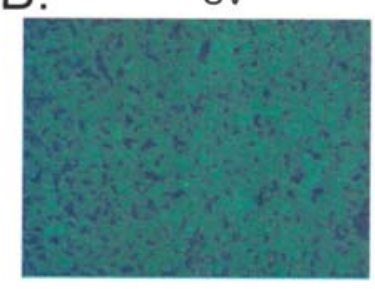

CTR RNAi

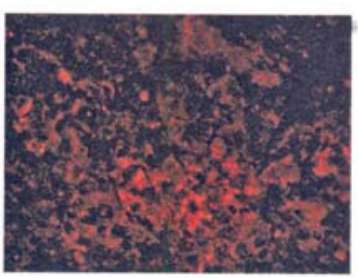

CTR RNAi

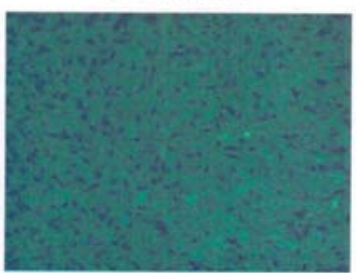

C.
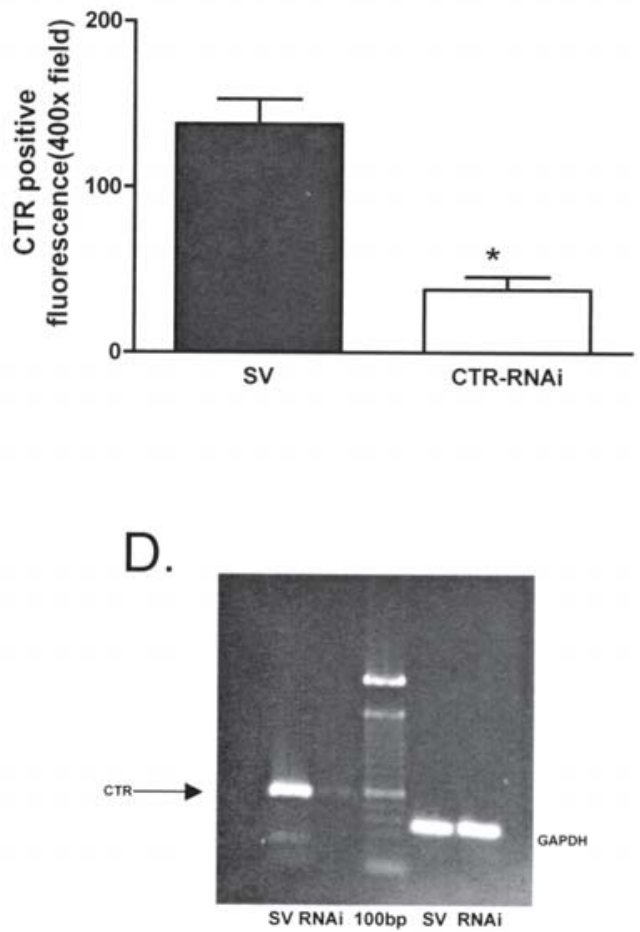

Figure 6. CTR expression in tumors treated with SV or CTR RNAi. The tumors treated with either SV or CTR RNAi were analyzed for CTR expression by CTR immunohistochemistry (A-C) and by real-time PCR (D). (A) Representative micrographs of SV- and CTR RNAi-treated tumor sections for CTR immunofluorescence in a x400 field. Paraffin-embedded tumor sections were processed for CTR immunofluorescence as described in the Materials and methods section. (B) Photomicrographs of corresponding sections of SV and CTR RNAi-treated tumors showing GFP expression in a x400 field. (C) Number of CTR-immunopositive cells per x400 field were counted. A total of 4 fields per section and four sections per tumor were examined. Each bar represents analyses of mean \pm SEM $(n=200)$, where the significant difference from controls is represented by an asterisk ( $<<0.05)$. (D) Abundance of CTR and GAPDH mRNAs in SV- and CTR RNAi-treated tumors. The mRNA levels for CTR and GAPDH were amplified by RT-PCR using specific amplimers as described in the Materials and methods section. An agarose gel was stained with ethidium bromide and photographed under UV light. DNA markers (100 bp) were electrophoresed as reference (all results are representative of at least three separate experiments.)

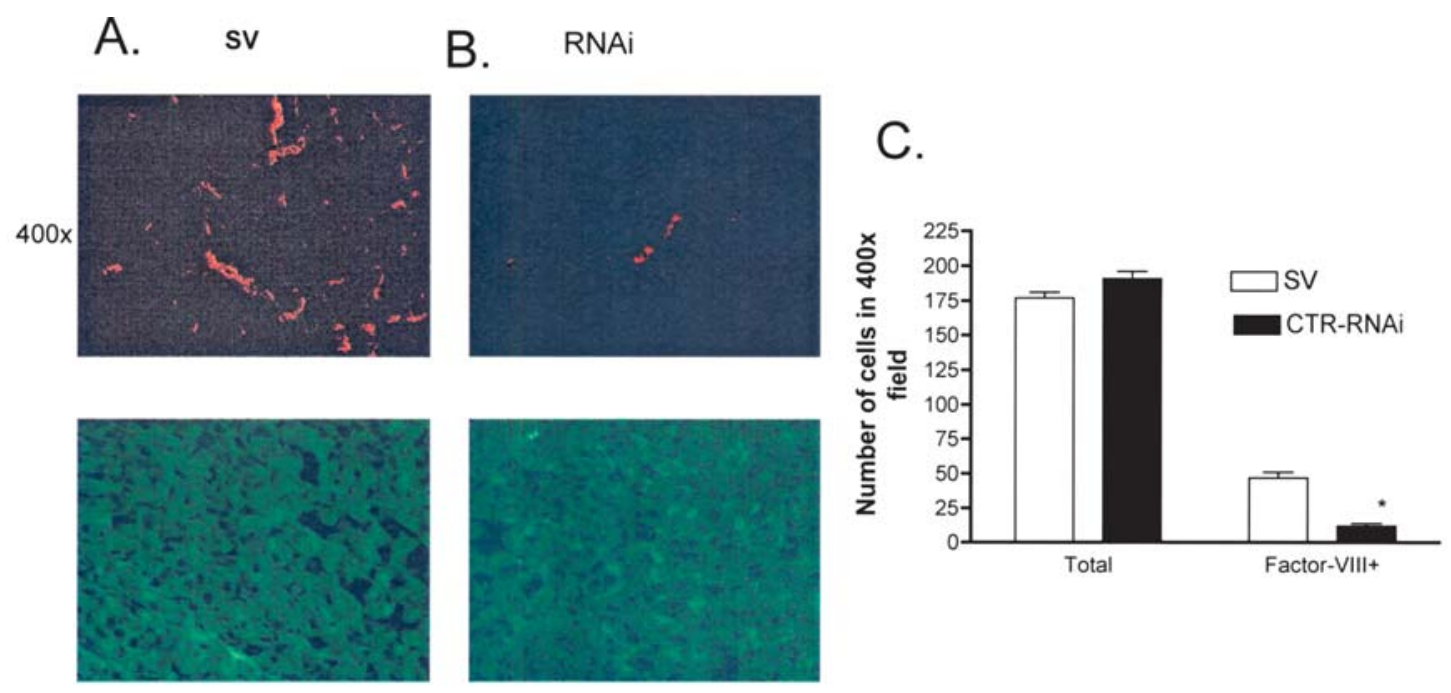

Figure 7. CTR RNAi treatment and angiogenesis in PC-3M xenografts. Representative photomicrographs of paraffin-embedded tumor sections of PC-3M tumor xenografts obtained after treating them with SV or CTR RNAi plasmids as described in Fig. 5. Sections of xenografts were treated with anti-factor VIII (Von Willebrand Factor) rabbit serum (1:200) for immunohistochemistry as recommended by the manufacturer (Dako). The micrographs (A-D) are representative of 3-4 sections for each of the tumor xenografts. (A) Representative micrograph of a section of PC-3M xenograft treated with SV plasmid. In the lower panel, photomicrographs of a corresponding section of SV-treated tumor showing GFP expression in a x400 field. (B) Representative micrograph of a section of PC-3M xenograft treated with CTR RNAi plasmid. In the lower panel, photomicrographs of corresponding section of CTR RNAi-treated tumor showing GFP expression in a x400 field. (C) Number of Factor VIII-immunopositive cells per x 400 field was counted. A total of 4 fields per section and four sections per tumor were examined. Each bar represents analyses of mean \pm SEM $(n=200)$, where the significant difference from controls is represented by an asterisk $(\mathrm{p}<0.05)$. 
A.

SV

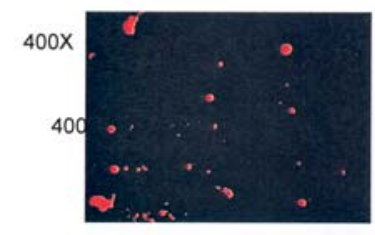

GFP

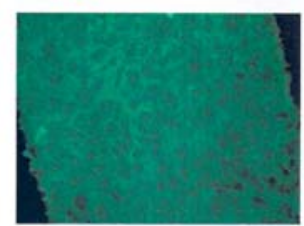

D.

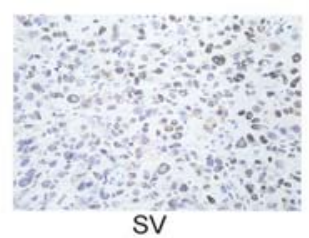

B.

CTR RNAi
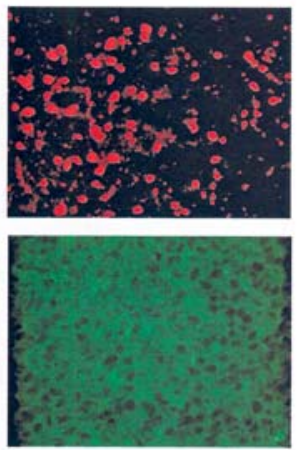

E.



C.

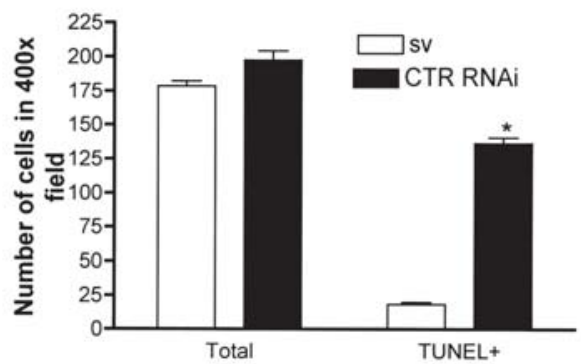

F.

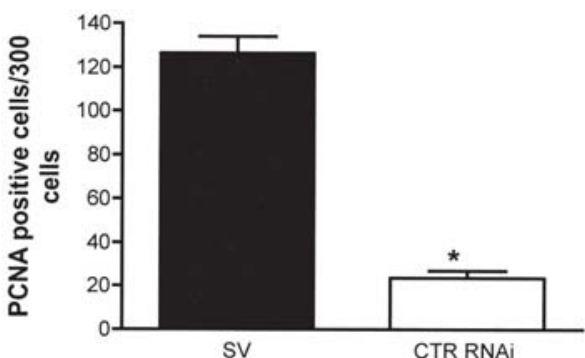

Figure 8. CTR RNAi treatment and tumor cell apoptosis. (A and B) Sections of xenografts were processed for apoptotic cells by TUNEL immunofluorescence using an Apoptag ${ }^{\mathrm{TM}}$ TUNEL kit, and the manufacturer's protocol was followed. The micrographs are representative of 3-4 sections for each of the SV and CTR RNAi tumor xenografts in a x400 field. Lower panel shows photomicrographs of corresponding sections of SV-and CTR RNAi-treated tumors showing GFP expression in a x400 field. (C) Bar diagram showing quantitative data of end-labeled cells from 3-4 random fields per section (of 4 sections per tumor) under a fluorescence microscope. Each bar represents analyses of mean \pm SD ( $n=70$ fields), where the significant difference from controls is represented by an asterisk $(\mathrm{p}<0.05)$. (D and E) Sections of xenografts were subjected to PCNA immunohistochemistry using Zymed PCNA IHC reagents, and manufacturer's instructions were followed. The micrographs are representative of 3-4 sections for each of the SV and CTR RNAi tumor xenografts in x400 fields. (F) Bar diagram showing quantitative data of PCNA-labeled cells from 3-4 random fields per section (of 4 sections per tumor) under a x400 field. Each bar represents analyses of mean $\pm \mathrm{SD}$ ( $\mathrm{n}=70$ fields), where the significant difference from controls is represented by an asterisk ( $<<0.05)$.

sv
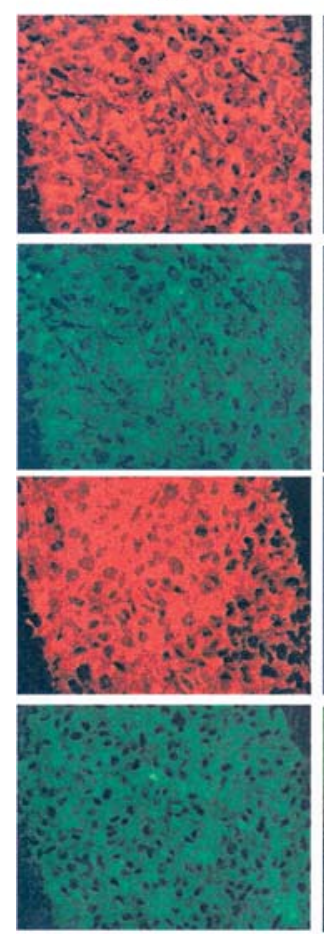

CTR RNAi
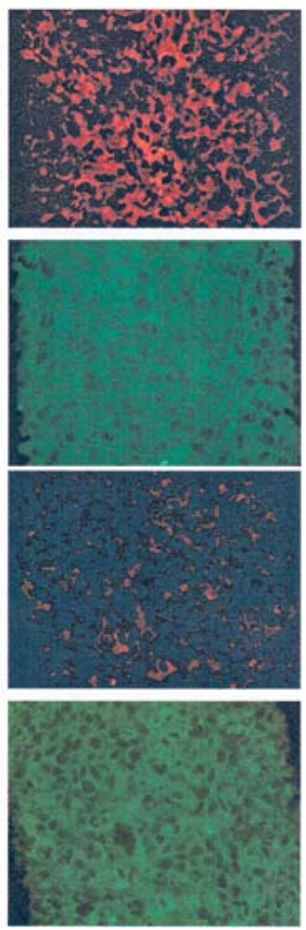

P-Akt

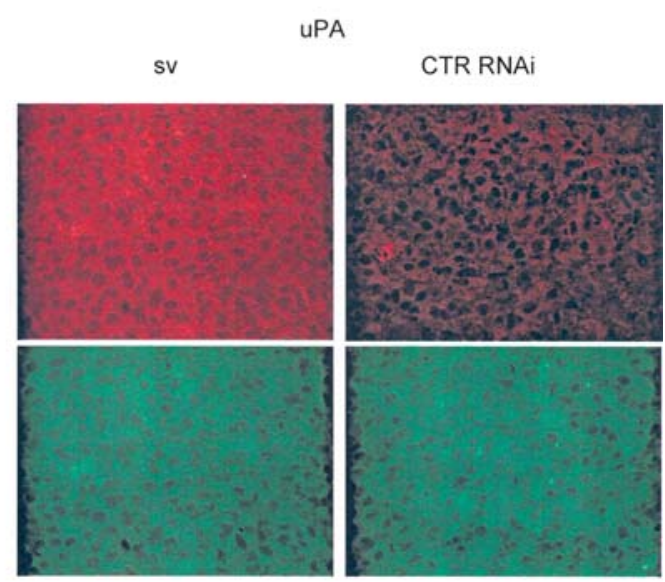

GFP

Figure 9. CTR RNAi treatment and phospho-Akt, survivin and uPA immunoreactivity. Sections of xenografts were subjected to phospho-Akt, survivin and uPA immunofluorescence using specific antisera as described in the Materials and methods section. The micrographs are representative of 3-4 sections for each of the SV and CTR RNAi tumor xenografts. Magnification is x400. In the lower panels of each micrograph, photomicrographs of corresponding sections of SV- and CTR RNAi-treated tumors showing GFP expression in a x400 field. 
Table II. Quantitative PCR for CTR transcripts in tumors treated with SV or CTR RNAi (Fig. 6D).

\begin{tabular}{lcccc}
\hline Sample & $\begin{array}{c}\text { Threshold } \\
\text { position }\end{array}$ & & $\begin{array}{c}\Delta \Delta \text { Ct value } \\
\text { value }\end{array}$ \\
\hline SV plasmid & 2.0 & 23.13 & 0 & 1 \\
injected & 2.0 & 23.00 & 0 & 1 \\
& 2.0 & 22.90 & 0 & 1 \\
CTR RNAi- & 2.0 & 25.83 & -2.7 & 0.431 \\
plasmid injected & 2.0 & 26.49 & -3.49 & 0.1776 \\
& 2.0 & 25.33 & -2.43 & 0.3856 \\
\hline
\end{tabular}

in vivo. At the time of necropsy, masses of tumors receiving SV plasmid (scrambled RNAi) were 10-fold greater than those receiving CTR RNAi (Fig. 5B). The efficacy of the gene transfer was demonstrated by the presence of GFP in tumors receiving either SV or CTR RNAi plasmids (Fig. 5C and D). Next, we analyzed the effectiveness of the RNAi administration on CTR knock-down in two ways. First, we examined the expression of CTR in the tumors by immunofluorescence. The results of Fig. 6A show that tumor sections receiving CTR RNAi displayed observably less CTR immunoreactive cell populations than those receiving the SV plasmid. However, both specimens contained a similar number of total cells as detected by GFP staining (Fig. 6B). Based on the average number of CTR-immunopositive cells per $\mathrm{x} 400$ field, CTR RNAi administration caused a three-fold decrease in CTR expression (Fig. 6C). We also analyzed CTR mRNA abundance in these tumors by real-time PCR using total reverse transcribed mRNA from tumors as templates. The results of Fig. 6D (lanes 1 and 2) and Table II show that the abundance of CTR mRNA in RNAi-treated tumors was 3-fold less than that in SV tumors (range 17-43\% for CTR RNAi tumors vs $100 \%$ for SV tumors).

CTR RNAi treatment and angiogenesis. H1-directed RNAi expression did not change the general architecture of tumors, and $H \& E$ staining showed largely comparable histology, except the presence of more tightly-packed cells in SV-treated tumors (Fig. 10). We then tested a possibility that the decreased cell density in CTR RNAi tumors may have been due to decreased angiogenesis and smaller endothelial cell population. We detected endothelial cell populations in tumor sections by endothelial-specific von Willebrand Factor immunofluorescence. The micrographs of Fig. 7A and B demonstrate remarkably less endothelial cell populations in CTR RNAitreated tumors. These results are consistent with our earlier results that PC cell-secreted $\mathrm{CT}$ is a potent angiogen. Counting of von Willebrand-positive cells in multiple $\mathrm{x} 400$ fields of tumor specimens revealed that CTR RNAi-treated tumors displayed 4-fold less endothelial cells per field than those receiving the SV RNAi (Fig. 7C).

CTR RNAi treatment and tumor cell viability. Since our earlier in vitro studies suggested that CT induces apoptosis resistance in prostate cancer cells, we tested a possibility that
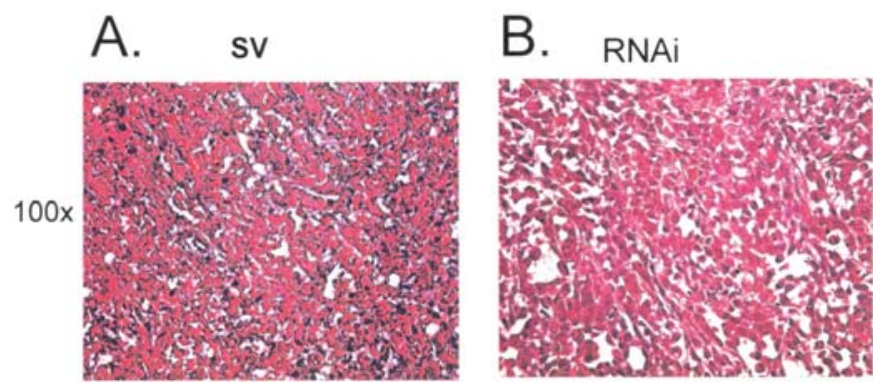

Figure 10. H\&E sections of SV and CTR RNAi tumors. Representative photomicrographs of paraffin-embedded tumor sections of PC-3M tumor xenografts obtained after treating them with SV or CTR RNAi plasmids as described in Fig. 5. (A) x100 H\&E section of PC-3M xenograft treated with SV plasmid; (B) x100 H\&E section of PC-3M xenograft treated with CTR RNAi plasmid.
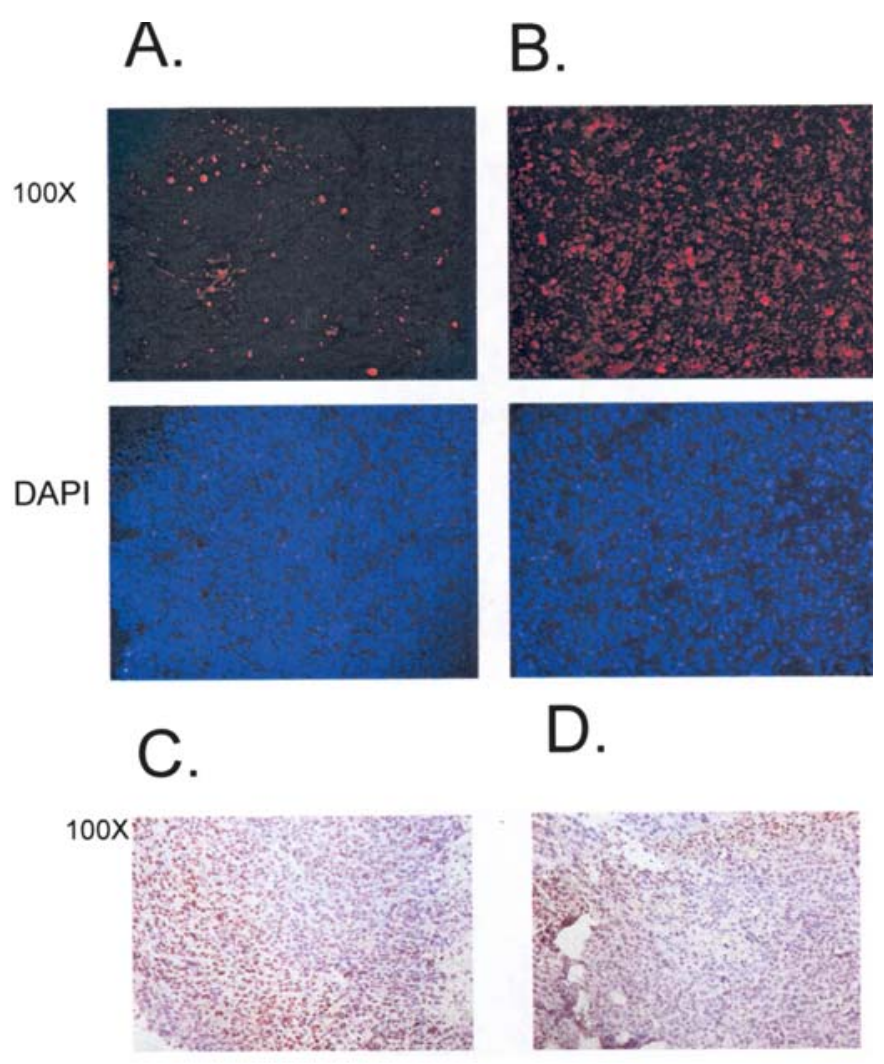

Figure 11. (A-B) Sections of xenografts were processed for apoptotic cells by TUNEL immunofluorescence using an Apoptag ${ }^{\mathrm{TM}}$ TUNEL kit, and the manufacturer's protocol was followed. The micrographs are representative of 3-4 sections for each of the SV (A) and CTR RNAi (B) tumor xenografts in a x100 field. Lower panel shows photomicrographs of nuclear staining of respective sections with DAPI to assess total number of cells in each $\times 100$ field. (C-D) Sections of xenografts were subjected to PCNA immunohistochemistry using Zymed PCNA IHC reagents, and manufacturer's instructions were followed. The micrographs are representative of 3-4 sections for each of the SV (C) and CTR RNAi tumor xenografts (D) in x100 fields.

the knock-down of CTR expression in vivo may induce apoptosis of tumor cells. We processed paraffin-embedded tumor sections from both treatment groups for TUNEL immunofluorescence. The results of Fig. 8A and B highlight significant differences in TUNEL-positive cell populations in tumors of two treatment groups. Tumors of SV-treated groups showed generalized, low TUNEL staining. In contrast, TUNEL staining 
in CTR RNAi-treated tumors was very high in several patches, and overall 7-fold greater (Fig. 8C).

Since proliferating cell nuclear antigen (PCNA) is produced during cell cycle progression, it is expressed in actively proliferating cells. The results of PCNA immunohistochemistry of tumor sections suggest that PCNA staining was uniform and distributed throughout in SV tumors. In contrast, it was irregular, and concentrated in patches in CTR RNAi-treated groups (Fig. 8D and E). These results raise a possibility that the parts of tumors receiving CTR RNAi did not have actively proliferating cells, whereas those parts not receiving CTR RNAi proliferated normally as seen in control groups. Counting of PCNA-positive cell population in these sections revealed a 5-fold decrease in proliferating cell populations of CTR RNAi-treated tumors as compared to SV-treated tumors (Fig. 8F).

CTR RNAi-induced changes in potential signaling molecules associated with CTR action. To investigate the possible impact of CTR knock-down on downstream signaling molecules, we investigated the distribution of phospho-Akt, survivin and urokinase type plasminogen activator (uPA) in CTR RNAiand SV-treated tumors. The results presented in Fig. 9 show a dramatic reduction in phospho-Akt, survivin and uPA immunoreactivity in CTR RNAi-treated tumors when compared with SV-treated tumors. These results are consistent with our earlier studies demonstrating CTR-stimulated uPA secretion and activation of PI3K-Akt-survivin pathway in PC cell lines.

\section{Discussion}

Earlier studies from this and other laboratories have shown that the exogenous addition of $\mathrm{CT}$ increases the invasiveness of LNCaP, PC-3M and DU-145 cell lines through Matrige ${ }^{\mathrm{TM}}$ $(10,14,16,17)$. Our results also suggest that CT induces apoptosis resistance and chemoresistance in $\mathrm{LNCaP}$ and $\mathrm{PC}-3 \mathrm{M}$ cells by activating PI-3-kinase-Akt-survivin pathway (18). Recently, we reported that LNCaP cells, which are CTRpositive but lack endogenous CT expression, are poorly tumorigenic and not invasive, but they acquire these characteristics with enforced CT expression $(11,19,20)$. In contrast, PC-3M cells lose their tumorigenicity and invasiveness with knock-down of CT expression. In the present study, we show a similar phenomenon in PC-3 cells, which lack endogenous CTR but express CT and are tumorigenic and invasive, and remarkably increase their rate of proliferation, tumorigenicity and invasiveness with enforced CTR expression. Considering that CT-CTR-positive cell populations in PC specimens are detected as early as high-grade PIN and display a positive correlation with the tumor grade (10), it is likely that activated CT-CTR autocrine axis plays an important role in the activation of functional pathways that are crucial in determining the phenotypes of advanced stage of cancers, such as increased proliferation, invasion, tumorigenicity, ability to form distant metastases and resistance to hormone and chemotherapy drugs. Therefore, a further understanding of the molecular events activated by CTR that increase the oncogenicity of prostate cancer cells is crucial to increase the understanding of fundamental molecular processes responsible for cancer progression.
If CTR stimulates the process(es) associated with oncogenicity of prostate cancer cells, then knock-down of its expression in highly invasive PC-3M cells should attenuate these processes. Multiple in vivo techniques have now been described to target specific genes in various cancers (21-23). For example, the use of a DNA-methylating agent (24), antisense oligonucleotides (22), siRNA oligonucleotides (25-27) or adenoviruses $(28,29)$ as targeting tools to suppress tumor growth has been reported. RNA interference (RNAi) has been suggested as a powerful tool to selectively silence the function of specific genes $(21,22,30)$. Instead of using conventional antisense technologies, which provide an attractive technique for transient and partial suppression of the gene of interest $(22,23,31)$, we used a plasmid-based RNAi approach. Once internalized in a cell, the plasmid uses a powerful RNA polymerase promoter to generate large intracellular concentrations of 21-nucleotide siRNAs specifically recognizing homologous CTR mRNA sequence. The intratumoral injection protocol used in the present study successfully delivered the plasmid to tumor cells, which effectively down-regulated CTR mRNA levels, CTR immunoreactivity as well as functional characteristics of CTR. The results suggest that PC-3M cells lacking functional CTR (as a result of CTR knock-down) displayed extremely poor tumorigenicity and either did not form tumors at all or formed extremely small tumors (as indicated by a 99\% decline in tumor masses as compared to vector control). Moreover, the administration of RNAi plasmids in preestablished xenografts attenuated their further growth, possibly by inducing growth arrest and/or apoptosis. Since no apparent deleterious effects were noted in CTR RNAi-treated animal groups, knock-down of CTR in pre-existing tumors can be used to effectively attenuate growth of CT/CTR-positive tumors.

In addition to providing a new therapeutic possibility, CTR RNAi plasmid therapy can be used as a tool to understand mechanisms associated with CTR-mediated increase in tumorigenicity. The present results suggest that decreased growth of CTR RNAi-treated tumors may have been due to growth arrest of tumor cells as well as their apoptosis, as indicated by a dramatic increase in PCNA-negative and TUNEL-positive cell populations. It is conceivable that the loss of CTR may predominantly lead PC-3M cells to apoptosis, and these cells will also lack PCNA. However, it is also likely that some PCNA-negative cells are viable, but in a quiescent phase. Additional studies will be necessary to determine the precise contribution of each process in CTR RNAi-mediated tumor growth inhibition.

Recently, we have shown that CT secreted by prostate cancer cells can serve as a potent angiogen, and stimulate angiogenesis with potency comparable to that of vascular endothelial growth factor (VEGF). We examined the effect of CTR RNAi treatment on tumor angiogenesis by analyzing endothelial cell populations in tumor specimens of both (CTR RNAi and scrambled RNAi) treatment groups. CTR RNAi-treated tumors displayed a four-fold decrease in endothelial cell population, suggesting that the CT-CTR autocrine axis provides a potent angiogenic signal to the growing xenograft. It remains to be examined whether the decrease in angiogenesis is predominantly responsible for a large increase in apoptotic and/or quiescent tumor cell populations or these two effects are independent. 
We also used an in vivo RNAi-treatment model to identify CTR-mediated signaling events associated with tumor growth. We observed that CTR RNAi-treated tumors displayed observably less uPA immunoreactivity, and remarkably lower phospho-Akt and survivin immunoreactivity. These results suggest that CTR activation in a growing tumor may activate uPA-uPAR axis as well as PI-3-kinase-Akt-survivin pathway, thereby, increasing the invasiveness and apoptosis resistance of tumor cells. These results are consistent with our earlier results of in vitro studies that CT stimulates the secretion of urokinase type-plasminogen activator (uPA), in a protein kinase A-dependent manner $(14,16,32)$, and also induces apoptosis resistance by activating PI-3-kinase-Akt-survivin pathway.

Coupling of UPA with uPAR has been shown to orchestrate the network of several different signaling molecules and generate multiple biological responses, such as proliferation, migration, invasion, angiogenesis, and metastasis (33-38). A previous study in human breast cancer cells showed that uPA-induced mitogenic activity requires activation of both Stat and ERK pathways (39). In contrast, our recent studies suggest that uPA-activated uPAR associates with $\alpha \mathrm{v} \beta 3$ integrins to stimulate prostate cancer (PC) cell migration on vitronectin and also mediates CT-induced FAK phosphorylation. It is likely that CTR stimulates PI3K-Akt-survivin pathway in PC cell lines through FAK-stimulation (18). A similar action of UPA-uPAR has also been reported in the glioblastoma cell line SNB 19 (34). These findings provide direct evidence of the critical role of CT-CTR axis in PC tumor growth and survival, and raise a possibility that the activated CT-CTR axis in primary PC endows a cancer cell with increased proliferative capacity and/or increased resistance to apoptosis.

In summary, the present results extend our previous findings that most tumor cells of metastatic prostate cancers co-express CT and CTR and demonstrate that the activation of CTR in prostate cancer cells significantly increases their cell proliferation, invasion, colony forming ability and tumorigenicity. These results not only explain results of our earlier studies but also provide significant new evidence that the knock-down of CTR expression in pre-existing tumors leads to a dramatic decline in their growth, supporting a possibility that activation of the CT-CTR axis plays an important role in progression of PC from a localized tumor to a metastatic phenotype. Direct molecular targeting against both CT and CTR would be a robust way to prove their biological contribution.

\section{Acknowledgements}

This study was supported by NIH grant CA96534 to GVS.

\section{References}

1. Presti JC Jr: Prostate cancer: assessment of risk using digital rectal examination, tumor grade, prostate-specific antigen, and systematic biopsy. Radiol Clin North Am 38: 49-58, 2000.

2. Thompson IM, Pauler DK, Goodman PJ, et al: Prevalence of prostate cancer among men with a prostate-specific antigen level $<$ or $=4.0 \mathrm{ng}$ per milliliter. N Engl J Med 350: 2239-2246, 2004.

3. Furuya $\mathrm{Y}$, Akakura K, Akimoto S, Inomiya $\mathrm{H}$ and Ito $\mathrm{H}$ : Pattern of progression and survival in hormonally treated metastatic prostate cancer. Int J Urol 6: 240-244, 1999.
4. Segawa N, Mori I, Utsunomiya H, et al: Prognostic significance of neuroendocrine differentiation, proliferation activity and androgen receptor expression in prostate cancer. Pathol Int 51: 452-459, 2001.

5. Vilches J, Salido M, Fernandez-Segura E and Roomans GM: Neuropeptides, apoptosis and ion changes in prostate cancer. Methods of study and recent developments. Histol Histopathol 19: 951-961, 2004.

6. Tilley WD, Buchanan G, Hickey TE and Bentel JM: Mutations in the androgen receptor gene are associated with progression of human prostate cancer to androgen independence. Clin Cancer Res 2: 277-285, 1996.

7. Miyake H, Nelson C, Rennie PS and Gleave ME: Acquisition of chemoresistant phenotype by overexpression of the antiapoptotic gene testosterone-repressed prostate message- 2 in prostate cancer xenograft models. Cancer Res 60: 2547-2554, 2000.

8. Kaibuchi T, Furuya Y, Akakura K, Masai M and Ito H: Changes in cell proliferation and apoptosis during local progression of prostate cancer. Anticancer Res 20: 1135-1139, 2000.

9. Howell SB: Resistance to apoptosis in prostate cancer cells. Mol Urol 4: 225-231, 2000.

10. Chien J, Ren Y, Qing Wang Y, et al: Calcitonin is a prostate epithelium-derived growth stimulatory peptide. Mol Cell Endocrinol 181: 69-79, 2001.

11. Thomas S, Chigurupati S, Anbalagan M and Shah G: Calcitonin increases tumorigenicity of prostate cancer cells: evidence for the role of protein kinase $\mathrm{A}$ and urokinase-type plasminogen receptor. Mol Endocrinol 20: 1894-1911, 2006.

12. Pfaffl MW: A new mathematical model for relative quantification in real-time RT-PCR. Nucleic Acids Res 29: e45, 2001.

13. Shah GV, Rayford W, Noble MJ, et al: Calcitonin stimulates growth of human prostate cancer cells through receptor-mediated increase in cyclic adenosine $3^{\prime}, 5^{\prime}$-monophosphates and cytoplasmic $\mathrm{Ca} 2+$ transients. Endocrinology 134: 596-602, 1994.

14. Chien J, Wong E, Nikes E, Noble MJ, Pantazis CG and Shah GV: Constitutive activation of stimulatory guanine nucleotide binding protein $(\mathrm{G}(\mathrm{S})$ alphaQL)-mediated signaling increases invasiveness and tumorigenicity of PC-3M prostate cancer cells. Oncogene 18: 3376-3382, 1999.

15. Shah GV, Chien J, Sun YP, Puri S and Ravindra R: Calcitonin inhibits anterior pituitary cell proliferation in the adult female rats. Endocrinology 140: 4281-4291, 1999.

16. Sabbisetti VS, Chirugupati S, Thomas S, et al: Calcitonin increases invasiveness of prostate cancer cells: Role for cyclic AMPdependent protein kinase $\mathrm{A}$ in calcitonin action. Int $\mathrm{J}$ Cancer 117: 551-560, 2005.

17. Larran J, Salido M, Aparicio J, Lopez A, de Palacio ML and Vilches J: In vitro characterization of bombesin and calcitonin on the proliferation of PC3, DU 145 and LNCaP cancer prostatic cell lines. Int J Dev Biol Suppl 1: 275S-276S, 1996.

18. Thomas S and Shah GV: Calcitonin induces apoptosis resistance in prostate cancer cell lines against cytotoxic drugs via the Akt/ survivin pathway. Cancer Biol Ther 4: 1226-1233, 2005.

19. Lim DJ, Liu XL, Sutkowski DM, Braun EJ, Lee C and Kozlowski JM: Growth of an androgen-sensitive human prostate cancer cell line, LNCaP, in nude mice. Prostate 22: 109-118, 1993.

20. Kozlowski JM, Fidler IJ, Campbell D, Xu ZL, Kaighn ME and Hart IR: Metastatic behavior of human tumor cell lines grown in the nude mouse. Cancer Res 44: 3522-3529, 1984.

21. D'Alessio S, Margheri F, Pucci M, et al: Antisense oligodeoxynucleotides for urokinase-plasminogen activator receptor have anti-invasive and anti-proliferative effects in vitro and inhibit spontaneous metastases of human melanoma in mice. Int $\mathbf{J}$ Cancer 110: 125-133, 2004.

22. Arens N, Gandhari M, Bleyl U and Hildenbrand R: In vitro suppression of urokinase plasminogen activator in breast cancer cells - A comparison of two antisense strategies. Int J Oncol 26: 113-119, 2005.

23. Miyagishi M, Hayashi $\mathrm{M}$ and Taira K: Comparison of the suppressive effects of antisense oligonucleotides and siRNAs directed against the same targets in mammalian cells. Antisense Nucleic Acid Drug Dev 13: 1-7, 2003.

24. Shukeir N, Pakneshan P, Chen G, Szyf M and Rabbani SA: Alteration of the methylation status of tumor-promoting genes decreases prostate cancer cell invasiveness and tumorigenesis in vitro and in vivo. Cancer Res 66: 9202-9210, 2006.

25. Salvi A, Arici B, De Petro G and Barlati S: Small interfering RNA urokinase silencing inhibits invasion and migration of human hepatocellular carcinoma cells. Mol Cancer Ther 3: 671-678, 2004. 
26. Gondi CS, Lakka SS, Dinh DH, Olivero WC, Gujrati M and Rao JS: Downregulation of UPA, uPAR and MMP-9 using small, interfering, hairpin RNA (siRNA) inhibits glioma cell invasion, angiogenesis and tumor growth. Neuron Glia Biol 1: 165-176, 2004

27. Jiang M, Rubbi CP and Milner J: Gel-based application of siRNA to human epithelial cancer cells induces RNAi-dependent apoptosis. Oligonucleotides 14: 239-248, 2004.

28. Alemany R, Gomez-Manzano C, Balague C, et al: Gene therapy for gliomas: molecular targets, adenoviral vectors, and oncolytic adenoviruses. Exp Cell Res 252: 1-12, 1999.

29. van Beusechem VW, Grill J, Mastenbroek DC, et al: Efficient and selective gene transfer into primary human brain tumors by using single-chain antibody-targeted adenoviral vectors with native tropism abolished. J Virol 76: 2753-2762, 2002.

30. Schweinitz A, Steinmetzer T, Banke IJ, et al: Design of novel and selective inhibitors of urokinase-type plasminogen activator with improved pharmacokinetic properties for use as antimetastatic agents. J Biol Chem 279: 33613-33622, 2004.

31. Pulukuri SM, Gondi CS, Lakka SS, et al: RNA interferencedirected knockdown of urokinase plasminogen activator and urokinase plasminogen activator receptor inhibits prostate cancer cell invasion, survival, and tumorigenicity in vivo. J Biol Chem 280: 36529-36540, 2005.

32. Sabbisetti VS, Chigurupati $\mathrm{S}$, Thomas $\mathrm{S}$ and Shah GV: Calcitonin stimulates the secretion of urokinase-type plasminogen activator from prostate cancer cells: its possible implications on tumor cell invasion. Int J Cancer 118: 2694-2702, 2005.
33. Andreasen PA, Kjoller L, Christensen L and Duffy MJ: The urokinase-type plasminogen activator system in cancer metastasis: a review. Int J Cancer 72: 1-22, 1997.

34. Gondi CS, Lakka SS, Yanamandra N, et al: Adenovirus-mediated expression of antisense urokinase plasminogen activator receptor and antisense cathepsin B inhibits tumor growth, invasion, and angiogenesis in gliomas. Cancer Res 64: 4069-4077, 2004.

35. Yebra M, Goretzki L, Pfeifer M and Mueller BM: Urokinasetype plasminogen activator binding to its receptor stimulates tumor cell migration by enhancing integrin-mediated signal transduction. Exp Cell Res 250: 231-240, 1999.

36. Langer DJ, Kuo A, Kariko K, et al: Regulation of the endothelial cell urokinase-type plasminogen activator receptor. Evidence for cyclic AMP-dependent and protein kinase $\mathrm{C}$-dependent pathways. Circ Res 72: 330-340, 1993.

37. Miyake H, Hara I, Yamanaka K, Arakawa S and Kamidono S: Elevation of urokinase-type plasminogen activator and its receptor densities as new predictors of disease progression and prognosis in men with prostate cancer. Int J Oncol 14: 535-541, 1999.

38. Rabbani SA and Xing RH: Role of urokinase (uPA) and its receptor (UPAR) in invasion and metastasis of hormone-dependent malignancies (Review). Int J Oncol 12: 911-920, 1998.

39. Jo M, Thomas KS, O'Donnell DM and Gonias SL: Epidermal growth factor receptor-dependent and -independent cell-signaling pathways originating from the urokinase receptor. J Biol Chem 278: 1642-1646, 2003. 